Original Article

\title{
The Limitations of Vocational Training Policies for Ethnic Minority Youth - A Case Study in Hoa Binh Province
}

\author{
Bui Thanh Minh* \\ VNU University of Social Sciences and Humanities, \\ 336 Nguyen Trai, Thanh Xuan, Hanoi, Vietnam
}

Received 20 September 2019

Revised 23 September 2019; Accepted 24 September 2019

\begin{abstract}
Vocational training for ethnic minority youth has been identified as an important solution to create sustainable livelihoods for people, narrowing the development gap among ethnic groups so as to ensure social security for the whole population. The Vietnamese state has enacted many policies to help young ethnic minority people participate in vocational training but the results are not as effective as expected. These restrictions come from not only the inside content of the policies themselves but also from the conditions in which they are implemented. The paper employs the ROCCIPI analytical framework and the quick survey results on vocational training for ethnic minority youth in Hoa Binh to provide an overview of these limitations and their impacts in reality. Keywords: Limitations, vocational traing support policies, ethnic minority youth, ROCCIPI, Hoa Binh province.
\end{abstract}

\footnotetext{
* Corresponding author.

E-mail address: buithanhminh88@gmail.com
}

https://doi.org/10.25073/2588-1116/vnupam.4197 


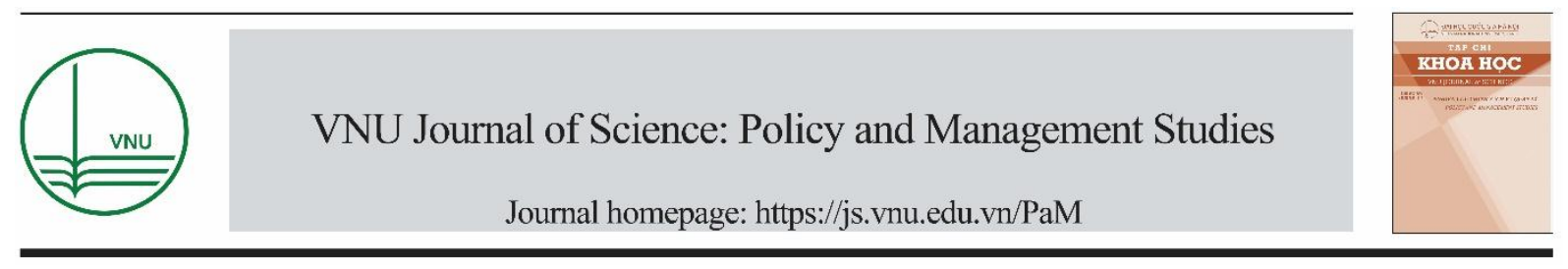

\title{
Những hạn chế trong hệ thống chính sách đào tạo nghề cho thanh niên dân tộc thiểu số - Nghiên cứu trường hợp tỉnh Hòa Bình
}

\author{
Bùi Thanh Minh* \\ Truoòng Đại học Khoa học Xã hội và Nhân văn, ĐHQGHN, 336 Nguyễn Trãi, Thanh Xuân, Hà Nội, Việt Nam \\ Nhận ngày 20 tháng 9 năm 2019 \\ Chỉnh sửa ngày 23 tháng 9 năm 2019; Chấp nhận đăng ngày 24 tháng 9 năm 2019
}

\begin{abstract}
Tóm tắt: Đào tạo nghề cho thanh niên dân tộc thiểu số được xác định là giải pháp quan trọng tạo sinh kế bền vững cho người dân, thu hẹp khoảng cách phát triển giữa các dân tộc, đảm bảo an sinh xã hội toàn dân. Nhà nước đã ban hành nhiều chính sách hỗ trợ thanh niên dân tộc thiểu số học nghề nhưng kết quả còn nhiều hạn chế. Những hạn chế này đến từ bản thân nội dung các chính sách cũng như những điều kiện để thực thi nó. Bài viết sử dụng khung phân tích ROCCIPI và kết quả khảo sát nhanh về đào tạo nghề cho thanh niên dân tộc thiểu số tỉnh Hòa Bình để cung cấp một bức tranh khái quát về những hạn chế này và tác động của nó đến thực tế.
\end{abstract}

Tù khóa: Hạn chế, chính sách đào tạo nghề, thanh niên dân tộc thiểu số, ROCCIPI, tỉnh Hòa Bình

\section{Bối cảnh chính sách}

Oxfarm năm 2013 dẫn số liệu của World Bank đã nhận định rằng người dân tộc thiểu số ở Việt Nam ngày càng tụt hậu trong quá trình phát triển ở góc độ quốc gia. Từ chiếm tỷ lệ $29 \%$ năm 1998, đến năm 2010, người dân tộc thiểu số chiếm tới $47 \%$ người nghèo cả nước [1]. Dù tỷ lệ nghèo của Việt Nam giảm nhanh qua các năm nhưng tình trạng nghèo ở dân tộc thiểu số ít được cải thiện dẫn đến phân cách càng ngày càng lớn. World Bank (2018) trong Báo cáo "Bước tiến mới: Giảm nghèo và thịnh vượng chung tại Việt Nam" cho thấy dù các hoạt động nông nghiệp giúp tăng thu nhập cho người dân tộc thiểu số nhưng các nhóm dân cư này vẫn chiếm $72 \%$ người nghèo ở Việt Nam [2]. Nghèo đói còn dẫn đển nhiều vấn đề làm giảm chất lượng cuộc sống của người dân tộc thiểu số trong đó có vấn đề kêt hôn sớm, hạn chế tiếp cận y tế, dịch vụ chăm sóc sức khỏe, giáo dục và các dịch vụ xã hội khác [3]. Năm 2004 chi tiêu của người dân tộc thiểu số bằng $59 \%$ mức chi tiêu của người Kinh, Hoa thì đến 2016 tỷ lệ này giảm xuống còn $52 \%$. Kết

\footnotetext{
*Tác giả liên hệ.

Địa chỉ email: buithanhminh88@gmail.com
}

https://doi.org/10.25073/2588-1116/vnupam.4197 
quả của sự chênh lệch ngày càng lớn này là đến từ tốc độ tăng trưởng cao của các hoạt động phi nông nghiệp và công việc được trả lương của người Kinh và người Hoa $[4, \mathrm{p} .11]$

Vấn đề cần đặt ra là chuyển đổi công việc và nâng cao hiệu quả hoạt động kinh tế cho các nhóm dân cư dân tộc thiểu số. Tuy nhiên, năng lực hạn chế, được thể hiện qua tỷ lệ người dân tộc thiểu số đã qua đào tạo chỉ chiếm $6.2 \%$, bằng $1 / 3$ mức trung bình của tổng thể dân số [3, p. 35]. Báo cáo quốc gia về thanh niên Việt Nam thông qua số liệu của Điều tra dân số 2009 cho thấy, $94.3 \%$ thanh niên dân tộc thiểu số chưa từng được đào tạo nghề [5]. Đây là một hạn chế trong việc hoạch định các chính sách hỗ trợ nhóm thanh niên dân tộc thiểu số trong việc phát triển bản thân, tạo sinh kế bền vững để hòa nhập xã hội. Hỗ trợ thanh niên dân tộc thiểu số học nghề, tìm kiếm việc làm là chính sách quan trọng nhằm giảm bất bình đẳng xã hội, hướng đến sự phát triển dung hợp, bền vững của vùng dân tộc thiểu số nói riêng và ở phương diện quốc gia nói chung.

Nhận thức được vai trò của đào tạo nghề cho thanh niên dân tộc thiểu số, Nhà nước đã ban hành nhiều chính sách hỗ trợ học nghề cho thanh niên dân tộc thiểu số. Rà soát của Bộ Lao động Thương binh và Xã hội năm 2018 cho thấy, Việt Nam có 116 chính sách khác nhau về đào tạo nghề, trong đó có 7 loại chính sách để hỗ trợ thanh niên dân tộc miền núi học nghề, nâng cao trình độ [6]. Có thể kể đến những chính sách quan trọng: Đào tạo nghề cho lao động nông thôn theo Quyết định 1956/2009/QĐ-TTg, Chính sách nội trú đối với học sinh, sinh viên học cao đẳng, trung cấp theo Quyết định 53/2015/QĐTTg, Quyết định 194/2001/QĐ-TTg về học bổng chính sách và trợ cấp xã hội đối với học sinh, sinh viên là người dân tộc thiểu số, Nghị định 86/2015/NĐ-CP về miễn giảm học phí, hỗ trợ chi phí học tập...Tuy nhiên, việc thực hiện các chính sách còn nhiều hạn chế dẫn đển hiệu quả đào tạo nghề cho thanh niên dân tộc thiểu số chưa bền vững [6].

Những hạn chế này đến từ nội dung các chính sách và cả các điều kiện thực tế để thực thi, do đó, bài viết sẽ sử dụng công cụ ROCCIPI để tìm hiểu và phân tích. Đây là một khung phân tích được World Bank khuyến nghị cho phân tích văn bản luật và chính sách để hiểu tác động của chính sách đến hành vi của các bên liên quan. ROCCIPI là viết tắt của 7 nội dung phân tích quan trọng của chính sách: Quy tắc (rules), Cơ hội (opportunity), Năng lực (capacity), Truyền thông (communication), Lợi ích (interest), Quy trình (process) và Ý thức hệ (Ideology) [7, p.134]

\section{Một số nghiên cứu về chính sách đào tạo nghề - Bài học từ một số quốc gia}

Nhận thức được tầm quan trọng của đào tạo nghề thông qua những tác động kinh tế - xã hội, các quốc gia và các tổ chức quốc tế luôn xác định và hỗ trợ việc xây dựng các mô hình đào tạo nghề phù hợp. World Bank (2013) xác lập vai trò quan trọng của đào tạo nghề và đề xuất việc hiện đại hóa hoạt động đào tạo nghề. Các quốc gia nền tăng cường phần dạy nghề trong hệ thống giáo dục, cải tiến hệ thống đào tạo nghề để theo kịp nhu cầu của thị trường lao động, qua đó giúp cho thanh niên dễ dàng hơn trong quá trình chuyển đổi để đi làm. Cụ thể, đào tạo nghề được cung cấp trong những năm trung học cần phải được hiện đại hóa, tăng tính thực hành và gắn kết với các cơ sở thực hành, thực tập. Việc thiết kế các chương trình đào tạo nghề cần tư vấn ý kiến của các nhà tuyển dụng thông qua mạng lưới hợp tác giữa các nhà tuyển dụng và các cơ sở đào tạo. Quan trọng hơn, để tránh việc coi đào tạo nghề như một lựa chọn cuối cùng thì cần thiết kế hệ thống đào tạo nghề có tính liên thông và dễ dàng chuyển đổi sang các bậc đào tạo cao hơn, trong đó có đại học. Cuối cùng, các hỗ trợ tài chính, giảm học phí cần được tính đến để huy động sự tham gia học nghề của người dân. Đối với các nước đang phát triển, cần đưa đào tạo nghề vào khu vực phi chính thức để tạo cơ hội nhiều hơn cho các tâng lớp dân cư tham gia, nâng cao hiệu quả hoạt động kinh tế, gìn giữ và phát triển các nghề thủ cồng truyền thống [8].

Chính phủ nhiều nước phát triển như Mỹ, Đức, $\mathrm{Na}$ Uy luôn đầu tư xây dựng hệ thống giáo dục nghề nghiệp chất lượng cao tuy nhiên mỗi 
quốc gia lại gặp những vấn đề riêng. Các chương trình đào tạo nghề tại Mỹ đa phần do các cơ sở tư cung cấp. Khoảng $30 \%$ dịch vụ đào tạo nghề được các trường cao đẳng cộng đồng giảng dạy hệ hai năm và có thể chuyển tiếp lên chương trình đào tạo đại học 4 năm. Các chương trình đào tạo nghề khác do các trung tâm đào tạo kỹ năng cho người lớn của chính phủ hoặc quân đội mở [9]. Tỷ lệ học nghề ở Mỹ tương đối cao, từ $36-48 \%$ vào những năm 1988 nhưng giảm liên tiếp vào những năm 2003 đến 2013, trước khi tăng trở lại vào 2015 [10].

Tại Pháp, hệ thống đào tạo nghề là hệ thống dựa vào các trường phổ thông [11]. Khi học sinh học lên cấp ba, các em có thể theo học các trường phổ thông kết hợp với dạy nghề hoặc trường trung học nghề. Tại $\mathrm{Na} \mathrm{Uy}$, hệ thống giáo dục dạy nghề (VET) được xây dựng dựa trên các nguyên tắc hợp tác ba bên: Chính phủ, doanh nghiệp và cơ sở đào tạo nghề [12-13]. Hai thách thức lớn hiện tại trong đào tạo nghề của Pháp là thúc đẩy sự nâng cao chất lượng và ứng phó với những thay đổi nhân khẩu học. Những cải cách lớn của hệ thống đào tạo nghề được thực hiện từ những năm 2000, trong đó năm 2002 giới thiệu hệ thống Đăng ký bằng cấp, năm 2004 chuyển giao trách nhiệm đào tạo về các Vùng phụ trách. Một đợt cải cách sâu rộng được tiến hành vào năm 2009 trong đó nhấn mạnh đến việc học tập suốt đời và sự hợp tác trong khu vực EU nhằm tạo ra tính linh hoạt trong đào tạo nghề [14].

Hệ thống đào tạo nghề tiên tiến tại Đức với các chương trình đào tạo nghề luôn cập nhật các xu hướng phát triển mới. Các cơ sở đào tạo nghề bám sát và đáp ứng nhu cầu của những thay đổi của nền kinh tế thông qua sự phối hợp chặt chẽ giữa doanh nghiệp và cơ sở đào tạo nghề. Đặc biệt, các hệ thống đào tạo nghề kép cho phép người học học kết hợp lớp học tại một trường dạy nghề và công việc tại một công ty [15]. Hệ thống này luôn được đánh giá là hình mẫu để các quốc gia khác tham khảo [16-17]. Dù thu nhập từ học đại học của Đức cao hơn so với trung học nhưng học nghề vẫn trở thành con đường phổ biến để đạt được các kỹ năng cần thiết để hướng đến một sự nghiệp thành công. Năm 2016, gần một nửa người Đức có chứng chỉ nghề chính thức
(47.2\%). Năm 2017, toàn bộ 1,3 triệu học sinh ở Đức đăng ký tham gia các chương trình giáo dục nghề nghiệp. Với cách thức đào tạo kép, kết hợp đào tạo thực tế tại nơi làm việc và lý thuyết trên lớp đã tạo những tác động kinh tế - xã hội tích cực đối với nước Đức. Tỷ lệ thanh niên thất nghiệp của Đức thấp nhất Liên minh EU và thấp hơn Hoa Kỳ (6.4\% so với 9.5\% năm 2017). Đồng thời, việc chuyển tiếp sang cuộc sống nghề nghiệp ngay từ khi là học sinh đã mở ra nhiều cơ hội nghể nghiệp, cũng cố liên kết và hòa nhập trong văn hóa, xã hội của nước Đức. Vì lý do này, nhiều quốc gia như Tây Ban Nha, Bồ Đào Nha, Hy Lạp, Ý, Latvia...đã học hỏi và chuyển đổi theo mô hình của Đức. Việt Nam cũng đang hợp tác cùng chính phủ Đức trong việc cải tiến, nâng cao hiệu quả của hệ thống đào tạo nghề [17].

Ngay cả với những nước phát triển trong khu vực Châu Á như Hàn Quốc, Singapore, Nhật Bản và những nước có sự tương đồng nhất định về kinh tế, xã hội với Việt Nam như Trung Quốc, Indonesia việc hoàn thiện hệ thống giáo dục dạy nghề luôn được chú ý thông qua nhiều loại hình đào tạo đa dạng từ bậc phổ thông và có sự tham gia của nhiều hệ thống đào tạo như công lập, ngoài công lập giữa chính phủ, chủ lao động, cơ sở đào tạo và người được đào tạo [18-21]. Ngoài ra còn có những tranh luận vào mức độ tham gia của nhà nước vào hoạt động đào nghề, các chính sách hỗ trợ cụ thể [22].

Tại Việt Nam, sau nhiều bất cập về quản lý, hiện nay hoạt động đào tạo nghề đã được đưa về quản lý thống nhất trong ngành lao động thương binh và xã hội. Hệ thống đào tạo nghề cũng bắt đầu tích hợp với giáo dục phổ thông, cũng đẩy mạnh sự liên kết các bên liên quan nhưng kết quả không cao dù nhà nước có nhiều chính sách hỗ trợ đào tạo nghề nói chung và đào tạo nghề cho các nhóm cụ thể như thanh niên, dân tộc thiểu số.

\section{Những kết quả nghiên cứu chính}

Chính sách và hoạt động đào tạo nghề cho thanh niên dân tộc thiểu số tỉnh Hòa Bình tuân theo quy định của nhiều văn bản khác nhau, 
trong đó có hai mảng chính: (1) đào tạo nghề cho lao động nông thôn với trình độ sơ cấp, ngắn ngày và (2) đào tạo tại các cơ sở đào tạo nghề với các trình độ trung cấp và cao đẳng. Đào tạo nghề cho lao động nông thôn do Sở Lao động Thương binh Xã hội và Sở Nông nghiệp và phát triển nông thôn phụ trách; đào tạo nghề tại các trường do 38 cơ sở đào tạo nghề trong đó có 03 trường cao đẳng trung ương thuộc các Bộ, 02 trường cao đẳng do tỉnh quản lý, 10 trung tâm giáo dục nghề nghiệp các huyện và các trường khác thuộc các đoàn thể như thanh niên, phụ nữ... Vấn đề của tỉnh Hòa Bình cũng là vấn đề mang tính phổ biến của nhiều tỉnh có người dân tộc thiểu số trong cả nước.

\subsection{Quy tắc (Rules)}

Hệ thống các văn bản có số lượng lớn đem đến khả năng quy định được nhiều vấn đề chi tiết, cụ thể từ mục tiều đến giải pháp thực hiện, phân bổ kinh phí... Tuy nhiên, mặt trái của nó là chồng chéo và cản trở hiệu lực của nhau.

Đối với đào tạo nghề cho lao động nông thôn, quyết định 971/2015/QĐ-TTg được ban hành để sửa đổi, bổ sung Quyết định 1956/2009/QĐ-TTg (Đề án "Đào tạo nghề cho lao động nông thôn đến năm 2020"). Đây là văn bản có vai trò quan trọng trong đổi mới công tác đào tạo nghề nhưng không xác định rõ cách thức đo lường hiệu quả công tác đào tạo, cách thức phân bổ nguồn kinh phí. Thêm nữa, các chính sách của Nhà nước chủ trương cho người dân học nhiều nghề nhưng nhà nước chỉ hỗ trợ cho một nghề dẫn đến cơ hội tiếp cận của người dân trở nên hạn chế. Điều 4, Quyết định 46/2016/QĐTTg phân ra 5 đối tượng với các mức độ hỗ trợ kinh phí khác nhau dẫn đến khó khăn trong áp dụng tại các địa phương vì không thể phân chia như vậy khi trong lớp có nhiều đối tượng.

Đối với đào tạo chuyên nghiệp, dù có chính sách hỗ trợ thanh niên dân tộc thiểu số học nghề nhưng các điều kiện đi kèm phải là hộ nghèo, hộ cận nghèo hay vùng đặc biệt khó khăn. Quyết định 53/2015/QĐ-TTg xác định đối tượng hưởng chính sách nội trú chỉ là "người thiểu số hộ nghèo, cận nghèo, người khuyết tật" thì không có nhiều sự khác biệt so với người Kinh "người dân tộc Kinh thuộc hộ nghèo, hộ cận nghèo hoặc là người khuyết tật có hộ khẩu thường trú tại vùng dân tộc thiểu số...”. Điều này dẫn đến nhiều thanh niên dân tộc thiểu số có nhu cầu học nghề bị hạn chế cơ hội tiếp cận và cũng không thực hiện được đúng chủ trương ưu tiên, hỗ trợ người dân tộc thiểu số học nghề trong hệ thống chính sách. Thậm chí, nhiều học sinh học trung cấp năm đầu được hưởng chính sách nội trú nhưng năm sau gia đình không được vào hộ nghèo nên không được hưởng tiếp, ảnh hưởng đển việc học tập [23]. Thậm chí, mức hỗ trợ cho học sinh dân tộc thiểu số học trong các trường đào tạo công lập được áp dụng từ 2002 đến nay vẫn ở mức 140.000 đồng/tháng theo Thông tư liên tịch số 13/2002/TTLT -BGD\&ĐT-BTC mà chưa có bất cứ sự điều chỉnh nào sau 17 năm là một bất cập nhìn thấy rõ của hệ thống chính sách.

\subsection{Co hội (Opportunity)}

Cơ hội ở đây là cơ hội vi phạm hay trục lợi chính sách. Nó được thể hiện phần nào qua việc giám sát thực hiện và đánh giá chính sách đào tạo nghề thiếu cơ chế và hướng dẫn cụ thể, dẫn đến những sai phạm, hạn chế.

Về chất lượng đào tạo, các văn bản không quy định rõ ràng việc đánh giá công tác đào tạo nghề của các cơ sở đào tạo; kinh phí quản lý dành cho đào tạo nghề ít, chủ yếu chỉ dùng cho hoạt động tổng kết, báo cáo. Các hoạt động kiểm tra mới dừng ở việc kiểm tra đối tượng, hồ sơ lớp học, chế độ thanh toán... Đây là kẽ hở để các cơ sở đào tạo chạy theo số lượng để nhận được hỗ trợ của Nhà nước mà bỏ qua yếu tố chất lượng và hiệu quả. Việc để các cơ sở tự đánh giá, báo cáo mà không có sự tham gia của bên thứ ba độc lập cũng tạo ra sự thiếu khách quan.

Nghị định 143/2016/NĐ-CP quy định rõ điều kiện đầu tư và hoạt động trong lĩnh vực giáo dục nghề nghiệp từ cơ sở vật chất, số vốn điều lệ, số giáo viên cơ hữu...Tuy nhiên, nhiều cơ sở chưa đủ điều kiện cũng được cấp phép gây ảnh hưởng đến chất lượng đào tạo. Tại Hòa Bình, khảo sát nhanh tại 3 trung tâm giáo dục nghề nghiệp cấp 
huyện, đều thiếu giáo viên dạy nghề, nhiều giáo viên văn hóa phải chuyển sang dạy nghề.

"Cả trung tâm có 5 giáo viên dạy nghề nên trung tâm bố trí cho các giáo viên văn hóa đi học nghề để dạy cho các em. Nếu năm sau nghề được dạy thay đổi thi lại phải tính tiếp. Trong khi giáo viên không có việc để làm thì vấn phải đi thuêe thinh giảng" - PVS lãnh đạo trung tâm giáo dục nghề nghiệp cấp huyện.

Đây không phải là vấn đề tại một địa phương mà xuất hiện trong phạm vi cả nước. Tại Quảng Ngãi, từ 2012-2015, 21 đơn vị đào tạo nghề chưa đủ giáo viên cơ hữu nhưng Sở Lao động Thương binh và Xã hội vẫn cấp giấy chứng nhận đủ điều kiện đào tạo nghề [24]. Thậm chí, việc đào tạo tại chỗ đối với các nghề cao đẳng để trục lợi chính sách cũng đã diễn ra. Kết quả thanh tra năm 2018 của Bộ Lao động Thương binh và Xã hội đã chỉ ra sai phạm của trường cao đẳng cơ điện Tây Bắc khi đào tạo 2179 học sinh tại 14 địa điểm ngoài trường trái quy định do không được cấp phép [25].

"Có trường cao đẳng về đây dạy nhưng người đi học toàn cán bộ xã để chuẩn bị bằng cấp để thi công chưc sau này. Dạy công nghệ thông tin thì ho bố trí cho 8-10 máy dịa phương, rồi cán bộ đem máy tính đi. Tâm lý đi học thi cũng chi cần tập tành biết cách tắt và mở soạn văn bản. Học viên tốt nghiệp viùa có bằng làm đẹp hồ sơ và có chúng chỉ tin học" - PVS cán bộ xã tại Hòa Bình
Các sai phạm về tài chính, quản lý chất lượng cũng được phát hiện tại nhiều cơ sở đào tạo và nhiều địa phương với con số hàng trăm tỷ đồng [26].

\subsection{Năng lực (Capacity)}

Năng lực thực thi chính sách của cơ quan quản lý nhà nước và năng lực đào tạo của các cơ sở đào tạo nghề trong việc đáp ứng nhu cầu của thanh niên dân tộc thiểu số còn hạn chế dẫn đến hiệu quả chính sách không cao.

Số cán bộ của hệ thống đào tạo nghề thuộc ngành Lao động Thương binh và Xã hội ở cấp tỉnh chỉ khoảng 5-7 người, trong đó có $3-5$ cán bộ của Phòng Dạy nghề của Sở, 01 cán bộ ở cấp huyện, 01 cán bộ cấp xã do đó nhiều khâu quan trọng đã bị bỏ qua hoặc không được thực hiện nghiêm túc. Đây là quy định chung của ngành lao động thương binh xã hội của cả nước.

Biểu đồ 1 cho thấy có đến $53.1 \%$ người dân được hỏi có nhu cầu được cán bộ hỗ trợ thụ hưởng chính sách về học phí học nghề, $41.1 \%$ mong muốn được cán bộ hỗ trợ vay vốn ưu đãi, $42.1 \%$ mong muốn được hỗ trợ tập huấn, chuyển giao kỹ thuật. Điều này sẽ gây áp lực lên bộ phận phụ trách đào tạo nghề tại các địa phương. Thực tế cho thấy, dù nhu cầu như vậy nhưng chỉ $33.1 \%$ người dân có nhu cầu hỗ trợ về học phí học nghề, $22 \%$ có nhu cầu vay vốn và $25.3 \%$ có nhu cầu tập huấn chuyển giao kỹ thuật sản xuất được cán bộ địa phương hỗ trợ.

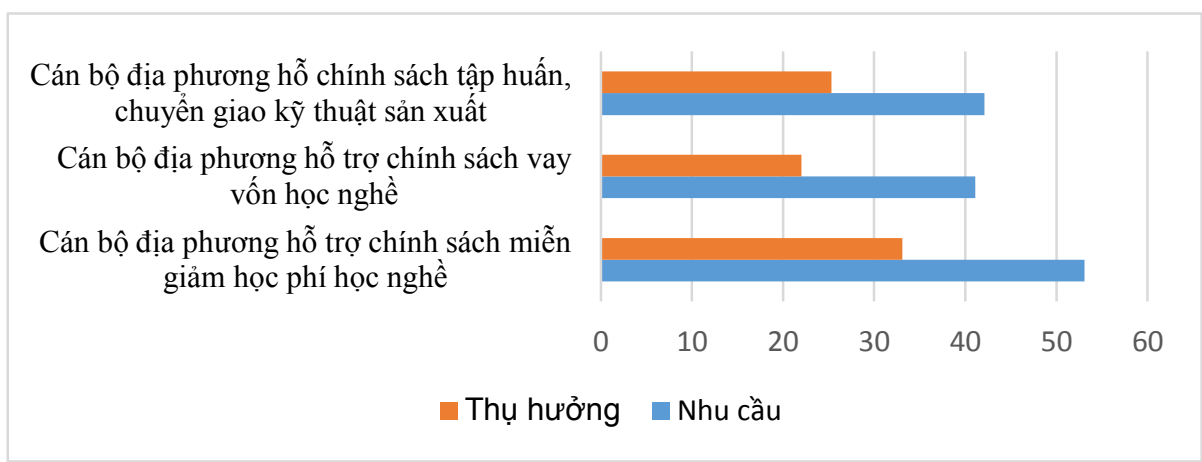

Biểu đồ 1 . Nhu cầu được hỗ trợ tiếp cận chính sách đào tạo nghề của người dân và mức độ đáp ứng (Đơn vị: \%) Kết quả khảo sát của tác giả tại Hòa Bình 
Hệ thống các trường đào tạo nghề tuy đã phát triển nhưng còn hạn chế về đội ngũ giáo viên, cơ sở vật chất, danh mục nghề nghiệp đào tạo... Danh mục các nghề chủ yếu tập trung vào nông nghiệp, trình độ tập huấn chỉ dừng ở mức độ sơ cấp, trung cấp do đó kết quả đào tạo nghề chưa đáp ứng được yêu cầu thực tiễn. Hòa Bình có 38 cơ sở đào tạo nghề nhưng $50 \%$ hoạt động không hiệu quả, có khả năng bị giải thể hoặc sáp nhập. 10 trung tâm giáo dục nghề nghiệp cấp huyện chỉ mới đủ năng lực dạy các nghề đơn giản như mây tre đan, chổi chít hay nuôi gà... theo Đề án Đào tạo nghề cho lao động nông thôn. Hai trường cao đẳng do tỉnh quản lý thì khó tuyển sinh, tổng số sinh viên của cả 2 trường trong năm 2019 chỉ khoảng 1400 học sinh, chủ yếu hệ trung cấp, trong đó có các lớp đặt tại các huyện với các nghề đào tạo đơn giản. Trong vòng 5 năm từ 2013 đến 2018, số lượng lao động được đào tạo của tất cả các cơ sở và các hệ đào tạo là 84.501 người, chủ yếu là sơ cấp (29.361 người) và dưới 3 tháng (43.731 người) [23].

\subsection{Truyền thông (Communication)}

Về mặt khách quan, người dân chưa có nhận thức đúng đắn về đào tạo nghề, xu hướng chủ yếu vẫn là lựa chọn việc học đại học. Truyền thông về giáo dục nghề nghiệp mang tính hình thức, một chiều nên chưa thể hiện rõ vai trò của đào tạo nghề, $x u$ hướng của việc sử dụng lao động trong bối cảnh hiện tại và tương lai, chính vì thế, xã hội nhìn chung vẫn giữ những định kiến tiêu cực về đào tạo nghề.
Một vấn đề cần đặt ra là số lượng thanh niên dân tộc thiểu số học cao đẳng rất hạn chế. Khảo sát tại tỉnh Hòa Bình cho thấy, cả 2 trường cao đẳng nghề của tỉnh đều không tuyển sinh được hệ cao đẳng. Nguyên nhân là do $90 \%$ thanh niên địa phương sau khi học xong trung học phổ thông đều tìm kiếm việc làm ngay, thậm chí mức lương tương đối cao chứ không lựa chọn học nghề. Số học sinh trung cấp tuyển được tại các trường nghề cũng chủ yếu đến từ hỗ trợ của chính sách nội trú.

"Học sinh trung họ phổ thông học xong là không thấy ai đi học trung cấp hay cao đẳng hết. Có khoảng 1000 em của Hòa Bình vào đại học, còn lại $9000 \mathrm{em}$ thì chủ yếu đi lao động phổ thông ở Bắc Ninh, Hà Nam. Ho cho người về tuyển tù khi đang học phổ thông với mức lương cam kết tì̀ $6-8$ triệu đồng nên rất khó để tuyển đi hoc nghề" - PVS lãnh đạo trường cao đẳng nghề.

"Nhiều em học xong còn phải giấu bằng nghề đi vì doanh nghiệp có xu huớng chỉ tuyền lao động phổ thông, vì có hợp đồng lao đào tạo và đỡ phải trả luoơng cao hơn" - PVS lãnh đạo trường cao đẳng nghề

Điều này cho thấy dù các hoạt động truyền thông về vai trò của đào tạo nghề, phân luồng giáo dục chưa thực sự hiệu quả. Thêm vào đó là ảnh hưởng bởi những chính sách không nhất quán trong việc thu hút, hỗ trợ thanh niên dân tộc thiểu số học nghề. Khảo sát nhanh 450 người dân ở 2 xã thuộc huyện Kim Bôi và Cao Phong cho thấy tỷ lệ người dân biết các thông tin hỗ trợ học nghề tương đối thấp với mức độ câu hỏi chỉ là có biết hay không?

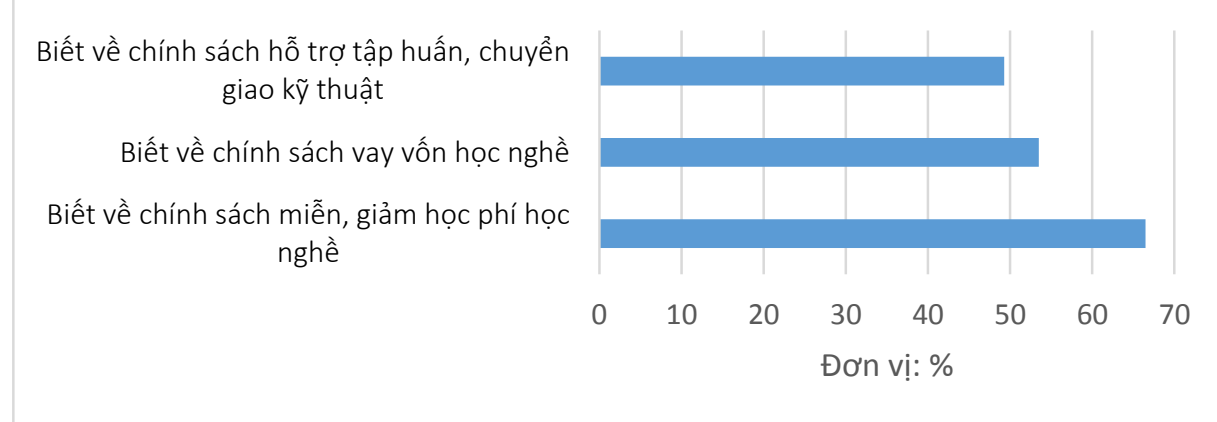

Biểu đồ 2. Tỷ lệ người dân biết về các chính sách hỗ trợ học nghề. (Kết quả khảo sát của tác giả tại Hòa Bình) 
Nguyên nhân truyền thông kém có thể đến từ hạn chế kinh phí. Nghiên cứu của Oxfarm (2017) chỉ ra theo Quyết định 971, Hội Nông dân là cơ quan chủ trì việc truyền thông, vận động nông dân học nghề, tuy nhiên Hội chưa được bố trí kinh phí cho hoạt động này [27].

\subsection{Lơi ich (Interest)}

Hệ thống các chính sách chưa tạo ra cơ chế lợi ích phù hợp để huy động sự tham gia của các doanh nghiệp, đối tác xã hội trong đào tạo nghề cho thanh niên dân tộc thiểu số dù đây là lĩnh vực tạo ra ngoại tác tích cực cho xã hội. Do tính chất công việc của doanh nghiệp trên địa bàn và các địa phương khác chủ yếu tuyển lao động phổ thông và đặc biệt theo Luật Lao động nếu tuyển lao động có đào tạo chứng chỉ sẽ phải trả lương cao hơn 7\% so với mức lao động phổ thông (Nghị định 157/2018/NĐ-CP) nên doanh nghiệp ít phối hợp cùng các cơ sở đào tạo nghề trên địa bàn.

Tồn tại mâu thuẫn quyền lợi trong quản lý nhà nước, phân bổ tài chính đào tạo nghề giữa Sở Lao động Thương binh và Xã hội và Sở Nông nghiệp và phát triển nông thôn trong đào tạo nghề cho lao động nông thôn.

Bảng 1. Đơn vị chủ quản của đào tạo nghề qua các năm

\begin{tabular}{|c|c|}
\hline Năm & Đơn vị chủ quản \\
\hline 2012 & Các cơ sở dạy nghề \\
\hline 2013 & Sở Lao động Thương binh và Xã hội \\
\hline 2014- & Sở Lao động Thương binh và Xã hội \\
\hline 2015 & phụ trách các nghề phi nông nghiệp \\
\hline & $\begin{array}{l}\text { Sở Nông nghiệp và phát triển nông } \\
\text { thôn nhu trách các nghề nông nohiên }\end{array}$ \\
\hline \multirow[t]{3}{*}{2016} & $\begin{array}{l}\text { Lồng ghép vào chương trình nông } \\
\text { thôn mới }\end{array}$ \\
\hline & $\begin{array}{l}\text { Sở Lao động Thương binh và Xã hội } \\
\text { quản lý chương trình đào tạo nghề }\end{array}$ \\
\hline & $\begin{array}{l}\text { Sở Nông nghiệp và phát triển nông } \\
\text { thôn phân bồ ngân sách }\end{array}$ \\
\hline
\end{tabular}

Trước năm 2016, theo Quyết định 971, Sở Nông nghiệp và phát triển nông thôn chưa có vai trò chủ đạo trong đào tạo nghề cho thanh niên dân tộc thiểu số. Đến năm 2016, khi chương trình đào tạo nghề theo Đề án 1956 được ghép vào Chương trình Nông thôn mới, ngành Nông nghiệp và phát triển nông thôn giữ vai trò phân bổ ngân sách đào tạo nghề trong khi ngành lao động giữ vai trò chủ trì tổng hợp kế hoạch kế hoạch đào tạo nghề. Điều đáng quan tâm là giữa hai ngành này không có cơ chế phối hợp tích cực, hiệu quả. Không có mô hình chung trong việc phân bổ ngân sách, mỗi địa phương lại có cơ cấu phân bổ khác nhau và thay đổi theo từng năm. Hòa Bình có tỷ lệ phân bổ ngân sách cho Sở Lao động Thương binh và Xã hội giảm từ 24,3\% xuống 17,6\% từ 2014 đến 2016; huyện, thành phố giảm từ $63,1 \%$ xuống $37 \%$; Sở Nông nghiệp và phát triển nông thôn tăng từ 12,6 lên $37,8 \%$ thì Quảng Trị lại tăng tỷ lệ phân bổ cho Sở Lao động Thương binh và Xã hội từ $15 \%$ lên $54,3 \%$; Sở Nông nghiệp và phát triển nông thôn giảm từ $15 \%$ xuống $10,2 \%$; huyện, thành phố giảm một nửa từ $70 \%$ xuống $35,5 \%$. Đây là một vấn đề phân mảng thể chế có tính nghiêm trọng [27].

Đối với đào tạo nghề tại các trường, do Quyết định 53/2015/QĐ-TTg chi trả trực tiếp cho đơn vị dạy nghề học phí và học bổng hỗ trợ cho học sinh diện nội trú nên các trường tăng cường tuyển sinh hệ 2 văn bằng đối với học sinh lớp 9 . Điều này có thể dẫn đến các cơ sở vì lợi ích của mình mà không hướng nghiệp nghề nghiệp thực sự phù hợp với học sinh mà chỉ nhằm mục đích thu hút các nhiều người học vào trường.

"Giờ sau quyết định 53/2015/QD-TTg về nọi trú thì cung tuyển được hệ 9+, nghĩa là 3 năm 2 bằng. Các em đi hoc được chính sách nội trú thì mới đi học nhung cái vuoóng là các truoòng cao đẳng nhu chúng tôi không được đào tạo văn hóa. Ra liên kết với bên giáo duc nghề nghiệp để đào tạo văn hóa thì khó khăn đủ đường. Ho không làm vẫn có lương nên ỳ. Chúng tôi đề xuất mở khoa giáo duc phổ thông trong truoơng cao đẳng để dạy văn hóa nhưng mà vướng mắc chính sách" - PVS lãnh đạo cao đẳng nghề tỉnh

Có thể thấy, dù chỉ trong phạm vi một địa phương nhưng vẫn tồn tại sự phân mảng thể chế do mâu thuẫn quyền lợi giữa ngành lao động và nông nghiệp; trong sự phân cấp giữa các trường đào tạo nghề trong nội bộ các trường đào tạo. 


\subsection{Quy trình (Process)}

Quy trình hỗ trợ đào tạo nghề cho thanh niên dân tộc thiểu số còn phức tạp, có sự chồng chéo về quản lý nhà nước giữa các cấp, ngành.

Về đào tạo nghề cho lao động nông thôn, bước lập kế hoạch cho đào tạo nghề vẫn đi theo hướng từ Sở Lao động Thương binh và Xã hội đến Phòng Lao động Thương binh và Xã hội và các xã. Phòng Lao động Thương binh và xã hội phối hợp với trung tâm dạy nghề huyện lập kế hoạch. Tuy nhiên, nhiều cơ sở khác do Đoàn Thanh niên, Hội Phụ nữ quản lý cũng lập kế hoạch dạy nghề dẫn đến chồng chéo, lãng phí nguồn lực. Đánh giá nhu cầu mang tính hình thức, chưa thực sự khảo sát người dân. Bước lập kế hoạch trung hạn tồn tại nhiều điểm yếu do quan liêu: Năm 2015, Bộ Lao động Thương binh và Xã hội yêu cầu các tỉnh lập kế hoạch đầu tư công trung hạn từ 2016-2020 đối với lĩnh vực dạy nghề. Năm 2016, Bộ Nông nghiệp và phát triển nông thôn yêu cầu các tỉnh lập kế hoạch đào tạo nghề nông nghiệp giai đoạn 2017-2020. Kế hoạch trung hạn của đào tạo nghề mang tính khả thi không cao do nhu cầu của người dân thay đổi theo các biến động kinh tế, thị trường lao động. Phân bổ ngân sách hàng năm chậm, gây khó khăn cho các cơ sở đào tạo nghề. Báo cáo của Oxfarm (2017) chỉ ra, năm 2014, ngân sách chuyển xuống các huyện vào khoảng tháng 4 , các lớp được triển khai từ tháng 5 trở đi. Năm 2015 và 2016 do phải xây dựng kế hoạch đào tạo trung hạn 2016-2020, thêm vào đó là phân bổ nguồn trong chương trình Nông thôn mới nên ngân sách chuyển xuống chậm hơn, các lớp đào tạo dồn xuống cuối năm gây ra sự lãng phí nguồn lực, hiệu quả đào tạo giảm sút do áp lực giải ngân, sự thay đổi nhu cầu của người dân [27]. Trong thực tế tại tỉnh Hòa Bình, ngân sách chỉ thực sự có từ tháng 6 dẫn đến các trung tâm giáo dục nghề nghiệp khó khăn trong việc sắp xếp các nghề phi nông nghiệp. Còn các nghề nông nghiệp thì lại phụ thuộc vào việc ngành nông nghiệp có thuê hay giao đào tạo cho trung tâm hay không vì liên quan đến quyền lợi quản lý và thực hiện.
"Mình không chủ động được, ngân sách năm nhiều năm it. Cứ khảo sát nhu cầu rồi đưa lên, thường là cắt đi các lóp. Xong đến tháng 6 mới biết minh được bao nhiêu, nhất là khi kinh phí gộp vào nguồn của Nông thôn mới. Có kinh phí rồi mới xem mở lớp nào, rồi thanh toán, rất bất cập" - PVS lãnh đạo trung tâm giáo dục nghề nghiệp huyện.

Đối với đào tạo nghề tại các cơ sở đào tạo, việc mở các ngành mới đáp ứng nhu cầu xã hội có liên quan đến nhiều vấn đề như đội ngũ giáo viên, cơ sở vật chất, giấy phép mở ngành. Các vấn đề này liên quan đến trách nhiệm nhà nước của Tổng cục giáo dục nghề nghiệp, Sở Nội vụ, Sở Tài Chính nhưng giữa các bên có nhiều bất cập trong phối hợp dẫn đến khó khăn đẩy về cho cơ sở đào tạo.

"Lên xin mở ngành trên Tổng cuc thì hỏi giáo viên đâu, co sở vật chất đâu để đảm bảo chất luợng đào tạo. Về tỉnh lên xin Sở Nội vu biên chế để tuyển người, xin Sở Tài chính ngân sách để đầu tư thi lại được hỏi là giấy phép mở ngành đâu. Mở được một ngành mới là mệt lắm" - PVS lãnh đạo trường cao đẳng nghề

Đây là những bất cập liên quan đến phân cấp, phân mảng thể chế do đó các chính sách khi thiết kế hay sửa đổi cần quy rõ trách nhiệm và cơ chế phối hợp của các bên liên quan trực tiếp và gián tiếp.

\section{7. Ý thúc hệ (Ideology)}

Văn hóa của người dân tộc thiểu số tác động tiêu cực đến hiệu quả của hoạt động và hiệu quả của đào tạo nghề. Nhìn chung, thanh niên dân tộc thiểu số không muốn làm ăn xa, đào tạo nghề xong, nếu không vay vốn phát triển kinh tế, thanh niên lại về làm nông nghiệp. Nhiều thanh niên đi làm xa được một thời gian cũng tìm cách trở về địa phương. Nhiều người dân tộc thiểu số sợ vay vốn, chấp nhận làm thuê.

Hơn nữa, xu hướng chung là ưu tiên học đại học. Số lượng các trường đại học nhiều, điểm đầu vào thấp, phân luồng chưa được chú trọng nên học sinh học hết Trung học phổ thông rất ít lựa chọn đi học nghề. Số không đi học đại học lại lựa chọn đi lao động phổ thông tại địa phương 
và các tỉnh thành khác do mức thu nhập ban đầu tương đối cao, lợi ích ngắn hạn thấy rõ hơn khi đi học nghề. Thêm vào đó là thói quen của người dân chỉ đi học khi được hỗ trợ kinh phí nên mục đích đi học nghề nhiều khi bị hạn chế [23, 28]

\section{Bàn luận}

Dựa vào khung phân tích ROCCIPI, có thể thấy hệ thống chính sách đào tạo nghề cho thanh niên dân tộc thiểu số có những hạn chế sau đây: (1) hệ thống văn bản chồng chéo, nhiều chính sách thiếu tính thực tiễn; (2) thiếu cơ chế đánh giá, giám sát dẫn đến việc vi phạm và trục lợi các chính sách của Nhà nước; (3) năng lực thực thi của các bên liên quan còn hạn chế dần đến nhu cầu thực sự của thanh niên dân tộc thiểu số chưa được đáp ứng một cách hiệu quả; (4) hiệu quả truyền thông chưa tốt dẫn đến hiểu biết của xã hội, gia đình và thanh niên về đào tạo nghề, các chính sách trợ giúp còn thấp dẫn đến việc đào tạo nghề ít được lựa chọn; (5) tồn tại sự phân mảng thể chế, sự mâu thuẫn quyền lợi giữa các cơ quản lý nhà nước trong lĩnh vực đào tạo nghề, tạo ra sự không nhất quán, kém hiệu quả của hoạt động đào tạo nghề; (6) quy trình chính sách có sự chồng chéo giữa các bên dẫn đến chậm trễ, lãng phí nguồn lực nhà nước và xã hội; (7) đào tạo nghề chưa được xã hội nhìn nhận đúng vai trò và tầm quan trọng nên học nghề ít được thanh niên dân tộc thiểu số lựa chọn. Những hạn chế này làm giảm hiệu quả của hệ thống chính sách và ảnh hưởng đến quá trình thụ hưởng quyền và dịch vụ đào tạo nghề của thanh niên dân tộc thiểu số.

Muốn nâng cao hiệu quả của hoạt động đào tạo nghề cho thanh niên dân tộc thiểu số cần giải quyết triệt để những hạn chế trên. Do đó, cần chú ý vào những giải pháp sau: (1) Rà soát và thay đổi những chính sách bất hợp lý; (2) Tăng cường các cơ chế giám sát hoạt động đào tạo nghề ở tất cả cấp độ; (3) Xem xét lại việc đầu tư cho cơ sở dạy nghề cấp huyện, nên đầu tư cho cơ sở dạy nghề cấp tỉnh sẽ tránh được lãng phí của việc đầu tư dàn trải và nâng cao năng lực của các cơ sở đào tạo nghề; (4) Huy động thêm sự tham gia của doanh nghiệp vào đào tạo nghề để có sự gắn kết giữa đào tạo và nhu cầu thị trường; (5) Tăng cường truyền thông về đào tạo nghề gắn với phân luồng mạnh mẽ giáo dục phổ thông, tạo tính liên thông trong đào tạo nghề và giáo dục đại học để đào tạo nghề trở nên hấp dẫn hơn đối với thanh niên dân tộc thiểu số; (6) Chuyển giao toàn bộ hoạt động đào tạo nghề cho ngành lao động thương binh và xã hội quản lý để tăng cường tính thống nhất trong chỉ đạo và thực hiện chính sách.

\section{Tài liệu tham khảo}

[1] Oxfarm, Tóm lược gợi ý chính sách: Bất bình đẳng gia tăng: Người dân nghĩ gì? Oxfarm, 2013. https://www.oxfamblogs.org/vietnam/wpcontent/uploads/2013/12/Perception-ofInequality-brief-VN-LR.pdf truy cập 30.04.2019

[2] World Bank, Báo cáo: "Bước tiến mới: Giảm nghèo và thịnh vượng chung tại Việt Nam”. World Bank, 2018.

[3] Phùng Đức Tùng, Nguyễn Việt Cường, Nguyễn Cao Thịnh, Nguyễn Thị Nhung, Tạ Thị Khánh Vân, Báo cáo: Tổng quan thực trạng kinh tế - xã hội của 53 dân tộc thiều số. Báo cáo tiểu dự án hỗ trợ giảm nghèo PRPP, Ủy ban dân tộc, 2017.

[4] Ministry of Labour, War Invalids and Social Affairs (MOLISA), Vietnam Academic of Social sciences and UNDP. Báo cáo nghèo đa chiều ở Việt Nam: Giảm nghèo ở tất cả các chiều cạnh để đảm bảo cuộc sống có chất lượng cho mọi người. 2017.

[5] Bộ Nội vụ và UNFPA, Báo cáo quốc gia về thanh niên Việt Nam, 2015.

[6] MOLISA, Nâng cao hiệu quả công tác truyền thông Giáo dục nghề nghiệp, 2018. http://www.molisa.gov.vn/vi/Pages/chitiettin.aspx ?IDNews=27732 truy cập 30.04.2019.

[7] Howard Stein, Beyond the World Bank Agenda: An institutional approach to development. The University of Chicago press, 2008.

[8] World Bank, Youth Unemployment and Vocational training. Background paper for the world development report 2013. 2013.

[9] L. Karen et al, Career and Technical Education in the United States Washington: 1990 to 2005, United States Department of Education, 2008.

[10] P. Campbell \& S. Laughlin, Participation in Vocational Education: An Overview of Patterns and Their Outcomes, The National Center for Research in Vocational Education, The Ohio State University press, 1988. 
[11] European Centre for the Development of Vocational training (CEDEFOD), Vocational Education and Training in France. Luxembourg: Office for Official Publications of the European Communities, 2016.

[12] M.Teemu \& L. Binshan, Continuing vocational training and innovation in Europe. International Journal of Innovation and Learning 11 (4) (2012) 325-338,

[13] S. Erik, Vocational Education and Training in Norway, and a VET pilot Project/certificate of Practice, Norwegian Ministry of Education and Research, 2012.

[14] Cedefop, Vocational education and training in France Short description. Luxembourg: Office for Official Publications of the European Communities, 2008.

[15] Federal Ministry of Economic Affairs and Energy, Federal Ministry of Labour and Social Affairs, Vocational training in Germany, 2016.

[16] Hans Peter Blossfeld, Is the German dual system a model for a modern vocational training system? International Journal of comparative Sociology XXXIII (1992) 3-4.

[17] Ann-Cathrin Spees, Could Germany's Vocational Education and Training System Be a Model for the U.S.?, 2018. https://wenr.wes.org/2018/06/couldgermanys-vocational-education-and-trainingsystem-be-a-model-for-the-u-s truy cập 30.04.2019

[18] Run-Zhi L et al, Vocational Education and Training in China: Introduction to Chinese Policy, 2011. http://sites.fordschool.umich.edu/chinapolicy/files/2011/10/PP716_VETPaper_Final_042911-1.pdf truy cập 30.04.2019

[19] Y. Doui, Public Vocational Training Frame work in Japan (chapter 15), in OECD Local Economic and Employment Development (LEED) Working Papers (2079-4797), 2012.

[20] OECD, Vocational Education and Training in Korea: Strenghts, Challenges and Recommendations, Report, 2009.

[21] TVET Provider Network, Overview of Indonesia TVET System, EAS TVET Provider Network Workshop, 2012.

[22] C. Greehalgh, Adult vocational training and government policy in France and Britain. Oxford Review of Economic Policy, Volume 15, Issue 1, March 1999, Pages 97-113, 1999.

[23] Sở Lao động Thương binh và Xã hội Hòa Bình (2018). Báo cáo Sơ kết 5 năm thực hiện Nghị Quyết số 29-NQ/TW (khóa XI) ngày 04/11/2013 về "Đổi mới căn bản và toàn diện giáo dục đào tạo, đáp ứng yêu cầu $\mathrm{CNH}$, $\mathrm{HĐH}$ trong điều kiện kinh tế thị trường định hướng XHCN".

[24] Nguyễn Triều, Nhiều sai phạm trong đào tạo nghề cho lao động nông thôn, 2017. http://baoquangngai.vn/channel/2024/201710/nhie u-sai-pham-trong-dao-tao-nghe-cho-lao-dongnong-thon-2848668/ truy cập 03.05.2019.

[25] Hoàng Long, Cao đẳng Cơ điện Tây Bắc đào tạo trái phép 2179 học sinh, 2018, Báo Thanh tra điện tử http://thanhtra.com.vn/tin-tuc-chong-thamnhung/dieu-tra/bo-nong-nghiep-va-phat-triennong-thon-buong-long-quan-ly-capduoi_t114c1076n137879 truy cập 2/9/2019.

[26] Thanh tra Chính phủ, Kết luận thanh tra số 3095/KL-TTCP năm 2012 về dạy nghề tại Bộ LĐTB\&XH, 2012.

[27] Oxfarm, Báo cáo "Nâng cao hiệu quả đào tạo nghề cho lao động nông thôn hướng đến giảm nghèo ở vùng DTTS". NXB Hồng Đức, 2017.

[28] Trung tâm giáo dục nghề nghiệp Kim Bôi, Báo cáo kết quả hoạt động năm 2018, 2018. 